\title{
O ADENSAMENTO URBANO CONSOLIDADO EM IGARAPÉS, COMO PROPOSTA PARA O DESENVOLVIMENTO LOCAL: O CASO DO PROSAMIM EM MANAUS.
}

\author{
Selma Paula Batista*
}

\section{RESUMO}

Tem sido destaque as obras urbanísticas executadas pelo Governo do Estado do Amazonas em áreas de igarapés urbanos, pelo Programa Social e Ambiental dos Igarapés de Manaus - PROSAMIM, financiado pelo Banco Interamericano de Desenvolvimento. No entanto, considerando as especificidades do ambiente urbano e os padrões térmicos de Manaus, este artigo, baseado em dados secundários, inicia uma reflexão para identificar se o modelo de adensamento urbano consolidado em igarapés apresenta indicadores para o desenvolvimento socioambiental proposto no nome do referido Programa, de modo a garantir com as ações, o mínimo impacto aos recursos existentes. Nesta perspectiva, o PROSAMIM concluído deverá atender as premissas do desenvolvimento, com: sustentabilidade social, viabilidade econômica e pertinência do modelo às características ambientais.

Palavras-chave: Desenvolvimento local, Sustentabilidade, Habitação, Igarapé, PROSAMIM.

\section{The URBAN CONSOLIDATION at the Iguarapés AS PROPOSED FOR LOCAL DEVELOPMENT:} THE CASE OF PROSAMIM IN Manaus.

\section{ABSTRACT}

Urban housing developments implemented by the State of Amazonas Government, integrated by The Social and Environmental Program for the Igarapés in Manaus - PROSAMIM, financed by the Inter-American Development Bank, have received a lot a attention. Nevertheless, considering the specificities of the urban environment and the thermal patterns of Manaus, this article, based solely on secondary data, intends to establish whether the model for urban human gatherings consolidated on igarapés grounds, shows any indication of socioenvironmental development, as proposed by the Program, so that the implementation of all the activities is insured not to cause any major impact on the existing resources. This way, when PROSAMIM project is concluded it will meet the development needs with: social sustainability, economic feasibility and maintenance of the model in accordance with the local environmental characteristics.

Key Words: Local Development, Sustainability, Housing, Igarapé, PROSAMIM

\section{Introdução}

Em sua essência a cidade de Manaus, dadas as condições do ambiente natural deste fragmento ao norte do território brasileiro, por situar-se no meio da floresta e na confluência dos rios Negro e Solimões, que do encontro formam o rio Amazonas, apresenta uma malha urbana diferenciada cujo sítio entrecortado por igarapés ${ }^{1}$ podem, no contexto da evolução do espaço

\footnotetext{
*Geógrafa pela UNESP, Mestre pela UFBA, Doutoranda em Geografia Humana Dinter/Minter, pela USP. Email: selmabatista@usp.br
} 
urbano, ser analisado como recurso e abrigo para a produção e reprodução das bases materiais de sobrevivência.

Como representação da relação estabelecida entre homem e natureza, a base da produção do urbano se define por meio das estruturas geográficas materializadas sobre a superfície terrestre. Está, suporte ecológico para a evolução do que Milton Santos (1996) define como formação socioespacial, resultado das formações históricas geograficamente localizadas. Teoria e método que permitem a leitura da cidade em sua essência e contradição. Fruto desta dinâmica, o espaço produzido retrata a história dos lugares.

No contexto deste artigo as formas de adensamento urbano com edificações subnormais em áreas de igarapé, justificam a relevância da leitura, primeiro para compreender em uma linha tempo-espaço desde a crise da borracha até o atual período econômico da Zona Franca de Manaus, sobre a influência do meio-técnico-científicoinformacional (SANTOS, 1997), os motivos responsáveis pela forma de uso dos igarapés e rios, como abrigo, por populações de baixa renda e recurso para um novo ordenamento do território, sob a forma de canalização dos córregos, promoção de espaços públicos de lazer e edificação de habitações de padrão popular, como proposta para o desenvolvimento local, com sustentabilidade socioambiental.

Como área de estudo o Igarapé de Manaus, na região central da cidade de Manaus é emblemático por possibilitar identificar a partir da investigação dos pressupostos para a intervenção e execução do Programa Social e Ambiental dos Igarapés de Manaus - PROSAMIM, a influência deste, quanto aos benefícios com o ordenamento socioespacial; como para identificar a estratificação das relações sociais estabelecidas durante o processo de negociação de remanejamentos e novos assentamentos urbanos que envolvem um programa desta magnitude. Considerando a pertinência de uso da metodologia de enfoque participativo adotado pelo Programa há de se analisar os paradoxos desencadeados em uma ação como está quando, num primeiro momento, para alcançar os objetivos traçados, o poder público potencializa as relações de identidade no território, criando mecanismos de gestão comunitária. E, num segundo, o próprio processo desarticula a base territorial, enquanto meta de um "planejamento", que visa a apropriação e uso do espaço, mais para fins políticos e econômicos, do que, efetivamente sociais e ambientais.

\section{O DESAFIO SOCIOAMBIENTAL EM UMA CIDADE COMO MANAUS}

Manaus surgiu e cresceu à beira do Rio Negro, adentrando os espaços de terra firme entre as principais bacias hidrográficas do São Raimundo e Educandos-Quarenta. Estas com o processo de evolução do espaço urbano, por situarem-se em área central da cidade, passaram também a ser ocupadas, por populações de baixo poder aquisitivo, em habitações irregulares em fileiras disformes de palafitas. Áreas cujo regime das águas do Rio Negro afeta diretamente no modo de vida destes habitantes que durante os meses de janeiro à junho - época da cheia, vivenciam a invasão das águas nos limites ou interior de suas habitações. E entre os meses de junho à dezembro - período da seca, ou de poucas chuvas, quando a vazante permite o aparecimento do campo de futebol; das várzeas; das áreas de pequenas plantações e criação de animais de pequeno porte; e, dos caminhos de terra que permitirão o ir e vir sem o uso das embarcações. No entanto, é também no período da estiagem que a beleza do modo de vida ribeirinho e da arquitetura das palafitas fica comprometida com a exagerada quantidade de lixo acumulado abaixo das habitações.

Cenário desastroso, de grande impacto socioambiental responsável não apenas pela subtração do belo da paisagem amazônica, expressa no modo de vida ribeirinho; mas, sobretudo, no aumento dos índices das doenças de veiculação hídrica, como leptospirose, hepatite A e enfermidades diarréicas agudas, causadoras dos elevados índices de mortalidade na região, segundo estatísticas publicadas pela Secretaria Municipal de Saúde do Amazonas.

Mesmos indicadores que, em escala global, incidem sobre outros países menos desenvolvidos, como os da África do Sul. Realidade discutida em paralelo à RIO92, na Cúpula de Joanesburgo 
que registrou na "Declaração de Joanesburgo", a necessidade de erradicação da pobreza, por meio de saneamento, água potável, habitação digna entre outras mudanças de padrões de consumo e uso dos recursos naturais, como alternativas para um crescimento com desenvolvimento.

Aplaudimos o foco da Cúpula de Joanesburgo na indivisibilidade da dignidade humana estamos resolvidos, através de decisões sobre metas, prazos e parcerias, a rapidamente ampliar o acesso a requisitos básicos tais como água potável, saneamento, habitação adequada, energia, assistência médica, segurança alimentar e proteção da biodiversidade. Ao mesmo tempo, trabalharemos juntos para nos ajudar mutuamente a ter acesso a recursos financeiros e aos benefícios da abertura de mercados, assegurar o acesso à capacitação e ao uso de tecnologia moderna que resulte em desenvolvimento, e nos assegurar de que haja transferência de tecnologia, desenvolvimento de recursos humanos, educação e treinamento para banir para sempre o subdesenvolvimento ${ }^{2}$.

No entanto, dada a racionalidade de três décadas desses eventos, pouco se evoluiu, desde Estocolomo, quando a problemática da degradação ambiental e deterriorização dos recursos naturais se tornaram pauta da mídia chamando a atenção, na RIO92, para os fundamentos a serem definidos para alcançar um desenvolvimento sustentável. Entretanto foi a partir de Joanesburgo ${ }^{3}$, que se passou a pensar o homem na perspectiva ambiental, despertando para a necessidade de resgatá-lo à dimensão da natureza enquanto parte integrante do ambiente que nele, pela sua força do trabalho causa impactos; mas dele, também precisa para a reprodução da sua base de sobrevivência (RIBEIRO,2008). Como defende Smith e Owens (1996) é necessário pensar o significado social do ambiente em uma perspectiva menos simplista e mais humanista de forma multidimensional. Para justificar citam Pepper (1987) e Weston (1986) ao argumentar que grupos de pressão fazem campanhas

[...] em favor do que consideram ser "natureza" - isto é baleias, focas, outros animais selvagens, a floresta tropical" enquanto demonstram escassa preocupação acerca dos ambientes daqueles que vivem, por exemplo, em conjuntos habitacionais no interior de cidades (para não falar nas condições desesperadoras na África, Ásia ou América Latina). Numa linha semelhante, Weston (1986, p. 2) insiste que "o ambiente é muito mais do que 'natureza'; é o mundo social, político, econômico e físico em que vivemos" (apud SMITH e OWENS, 1996, $\mathrm{p}, 127)$.

Com este foco vale lembrar Milton Santos ao argumentar que "a mundialização do planeta unifica a natureza" (1997:19). Unificada ela perde em sua especificidade a essência dos lugares que assumem, como ambientes, a complexidade da racionalidade resultante de "um conjunto de abstrações homogêneas", como citam (SMITH e OWENS 1996:154). E de forma paradoxal, a complexidade deste conjunto, pela perversidade dele inerente, é que possibilita a promoção de um desencadeamento para o desenvolvimento local. Conceito amplo e que necessita ser analisado mais em uma concepção social, do que como resultado de investimentos em infra-estrutura ou aumento do produto interno bruto - PIB, esses indicadores mais associados à vida política e econômica de um país, em geral, responsáveis por mascarar a realidade social.

Brose (2000) citando Amartya Sen (1999), Prêmio Nobel da Paz em 1998, que, pelos resultados obtidos no estado de Kerala, no sul da Índia, mediante a redução das desigualdades sociais tornou-se referência internacional de região pobre com excelente Índice de Desenvolvimento Humano - IDH, defende desenvolvimento como processo de realização pessoal.

Existem dois modelos para encarar o desenvolvimento no mundo atual. Um, 
fortemente influenciado pela economia do crescimento e seus valores básicos, define desenvolvimento essencialmente como uma expansão rápida e continua do produto nacional ( ou doméstico) bruto per capita, talvez um pouco mais qualificado pela exigência que os frutos desta expansão alcancem todas as parcelas da comunidade. Eu irei chamar este de a 'visão de opulência do desenvolvimento'. Nesse enfoque, os valores sociais e a cultura não têm papel relevante. O segundo modo, contrastante, vê o desenvolvimento como um processo que fortalece a liberdade daqueles envolvidos na busca dos seus objetivos individuais, sejam esses quais forem. Nesse enfoque, eu chamarei de a 'visão da efetiva liberdade de desenvolvimento', a importância da opulência econômica depende dos valores das pessoas envolvidas, e portanto é condicionada culturalmente. Nesse sentido, a expansão da capacidade humana pode ser descrita como a característica central do desenvolvimento (SEN, 1999 apud BROSE, 2000, p. 32).

Com o mesmo enfoque ao segundo modo acima citado, que conceitua o desenvolvimento como um processo libertário, Buarque (1999) define desenvolvimento na escala local, como

[...] um processo endógeno registrado em pequenas unidades territoriais e agrupamentos humanos capaz de promover o dinamismo econômico e a melhoria da qualidade de vida da população. Representa uma singular transformação nas bases econômicas e na organização social em nível local, resultante da mobilização das energias da sociedade, explorando as suas capacidades e potencialidades especificas (BUARQUE, 1999, p.10).

Sendo o espaço geográfico instância social carregado de significados, um planejamento com foco no desenvolvimento local deve levar em conta as potencialidades e especificidades de cada lugar como fator determinante para um desenvolvimento sustentado.

Por desenvolvimento sustentado, entende-se a evolução teórica do conceito de ecodesenvolvimento de Ignacy Sacks, cunhado no ano de 1974, cuja expressão consolidada no Relatório Que Faire, de 1975, a partir de 1983, passará a ser referência entre a comunidade internacional nas discussões e textos dos trabalhos da Comissão Mundial para o Meio Ambiente e Desenvolvimento (CMMAD) ${ }^{4}$

Ribeiro (2008) citando Ribeiro et. al (1996) fundamenta e argumenta os paradoxos que passam a vigorar a partir da evolução e uso do conceito de sustentabilidade ao longo destes eventos. Para o autor este,

[...] poderia vir a ser uma referência, desde que servisse para construir novas formas de relação entre os seres humanos e destes com o ambiente. Apontam que o grande paradoxo do desenvolvimento sustentável é manter a sustentabilidade - uma noção das ciências da natureza - com o permanente avanço na produção exigida pelo desenvolvimento, cuja matriz está na sociedade" (RIBEIRO et al,. 1996 apud RIBEIRO, 2008, p.113).

Ainda de acordo Ribeiro (2008) se o principio do conceito de desenvolvimento sustentável é

conciliar crescimento e preservação ambiental [...] por sua vaguidade, passou a servir a interesses diversos. De nova ética do comportamento humano, passando pela proposição de uma revolução ambiental até ser considerado um mecanismo de ajuste da sociedade capitalista (capitalismo soft), o desenvolvimento sustentável tornou-se um discurso poderoso promovido por organismos internacionais, empresários e políticos, repercutindo na sociedade civil internacional e na ordem ambiental internacional (RIBEIRO, 2008, p.113). 
Fundamentado no conceito de desenvolvimento local e sustentado e na complexidade de sua materialização por meio de um conjunto de estruturas no processo de evolução do espaço urbano, se investiga o perfil do Programa Social e Ambiental dos Igarapés de Manaus - PROSAMIM, na perspectiva de ampliar a reflexão sobre a imposição de modelos prontos sem a análise das especificidades e potencialidades locais, visando à maximização dos benefícios socioambientais.

\section{O PROGRAMA PROSAMIM}

O Programa Social e Ambiental dos Igarapés de Manaus - PROSMAMIM tem como objetivo contribuir para a solução dos problemas ambientais, urbanísticos e sociais de Manaus, com proposta direcionada para as Bacias dos Igarapés EducandosQuarenta e São Raimundo, localizadas em áreas centrais da cidade, inundáveis em épocas de cheia.

Dividido em duas etapas, o Governo do Estado com administração da Unidade de Gerenciamento do Programa Social e Ambiental dos Igarapés de Manaus - UGPI, e recursos do Banco Interamericano de Desenvolvimento e Governo Federal, implantou o PROSAMIM I e está em andamento o PROSAMIM II. A importância de execução deste Programa para o Estado se deve a necessidade de planejar o ordenamento socioespacial da capital do Amazonas, cujas formas de ocupação em áreas de rio, iniciadas após a decadência do ciclo econômico da borracha, com a chamada "cidade flutuante" (OLIVEIRA, 2003) e das áreas de igarapés, que se adensaram por ocasião da criação da Zona Franca de Manaus, em 1967, ano em que a cidade vivenciou um boom populacional. Da década de 1970 , até a última contagem do IBGE em 2007, a população de Manaus aumentou, respectivamente, de 311.622 para 1.646.602 habitantes. Moradores, em geral oriundos do interior do estado do Amazonas e também migrantes vindos do nordeste, sul e sudeste do país, atores responsáveis pela história da estratégia de ocupação e produção do espaço amazônico, pensado durante o regime militar com o Plano de Metas do Presidente Juscelino Kubitschek (1956-1961) culminando com as ações dos governos seguintes de João Goulart (1961-1964), Castelo Branco (1964-1967), Costa e Silva (19671969), Médici (1969-1974) e Geisel (1974-1979) e respectivos governadores do Amazonas. Ações que promoveram com obras de infra-estrutura - volumosas em investimentos e endividamento financeiro -, como a Transamazônica, uma ampla e desastrosa apropriação e uso do espaço amazônico com repercussões diretas na criação de novos núcleos populacionais sem infra-estrutura urbana.

Como reflexo e condicionante dos modos de produção da sociedade, a evolução do urbano na cidade de Manaus tem ponto de partida nos períodos áureos do ciclo da borracha com um ordenamento territorial baseado no modelo europeu, financiado pelos seringalistas com obras de estrutura urbana e edificação de grandes monumentos, hoje Patrimônio Histórico Edificado da cidade de Manaus. Conforme citação,

A capital do látex adquire nova fisionomia, corrigem-se acidentes de terrenos, organizase diagrama de nivelamento da cidade a fim de estabelecer normas aos novos projetos de construção, aterra-se igarapés, estes muitas vezes usados como via de comunicação, fonte de abastecimento d'água e local de lazer. (DIAS, 1999, p.37 apud OLIVEIRA, 2003, p.74)

Seguindo com a criação da Zona Franca de Manaus - ZFM, estes ciclos econômicos respondem pelos modelos de ordenamento territorial excludente e segregador, típico de cidades planificadas que instaura na aparente "ordem" planejada uma "desordem" nos modos de ocupação e produção dos espaços que, como dito, no contexto amazônico, levaram o adensamento populacional à ocupação de igarapés situados em área central urbana. Estes, enquanto forma, ao longo das décadas de 1970 a 1990, foram mudando sua função (SANTOS, 1996) passando de áreas de balneário a espaços do habitar, com edificações disformes de paus fincados sob o leito do rio, equilibrando estruturas de madeira, sem sistema de saneamento, ou abastecimento de água.

Segundo dados do Governo do Estado (PROSAMIM, 2008), o Programa Social e Ambiental do Igarapé de Manaus implementado prevê atender 
aproximadamente 8 mil famílias, 5 mil na Bacia do Educando-Quarenta e 3 mil em outros igarapés de Manaus. O PROSAMIM I teve início em 2003, mas, apenas em 2006, as obras físicas começaram, com investimentos obtidos em forma de empréstimo junto ao BID no valor de US\$200 milhões. Do total, US\$ 60 milhões foram contrapartida do Governo do Estado do Amazonas e US\$140 milhões do BID, tendo como fiador a República Federativa do Brasil, mediante as seguintes condições: amortização de 25 anos; período de carência de 6 anos; período de desembolso de 6 anos; taxa de juros Libor; sem comissão de inspeção e vigilância; comissão crédito de $0,25 \%$.

Os recursos destinados ao PROSAMIM I deveriam atender as áreas do Igarapé do Educandos-Quarenta e São Raimundo - já sentido bairro. No entanto, o segundo será contemplado no PROSAMIM II, tendo sido na primeira etapa atendidas as áreas do igarapé EducandosQuarenta a partir da foz do Rio Negro e Igarapés Manaus, Bittencourt, Mestre Chico e Cachoerinha. Segundo o documento do BID (2005) 5 as obras do PROSAMIM I, envolveram projetos de engenharia para a recuperação da função de drenagem dos igarapés; promoção do ordenamento urbano e reassentamento dos moradores, anteriormente, residentes em áreas de risco e inundações; criação de parques recreativos e equipamentos públicos de serviço e convivência social; melhorias do sistema viário nas áreas do entorno ao projeto; implantação dos serviços de saneamento básico em áreas de intervenção; melhoria na capacidade operacional e de gestão dos organismos envolvidos com o Programa; promoção efetiva da comunidade na fase de construção e manutenção das obras para promover a sua sustentabilidade.

Aqui vale a pena retomar o conceito de sustentabilidade acima apresentado que pressupõe a valorização das potencialidades e especificidades de cada lugar como fator determinante para um desenvolvimento sustendo. Neste contexto, o aterramento e canalização dos igarapés, construção das unidades habitacionais seguindo um modelo padronizado e o fomento da participação popular apenas para legitimar as ações, inviabilizam pensar o Programa neste contexto, visto não ter, para contrapor o modelo proposto, outro que garantisse a existência dos igarapés em detrimento à canalização e o aterramento. Pensar o desenvolvimento local é pensar formas de garantir o mínimo impacto com a máxima utilização dos recursos existentes, tanto naturais como os sociais, por meio do compartilhamento do saber tradicional das populações residentes nestas áreas.

De qualquer modo, se entende que um projeto que valorizasse o saber tradicional, potencializando a educação ambiental como pressuposto para manter os igarapés urbanos no desenho de um novo ordenamento para a cidade de Manaus, demandaria um tempo que os projetos que contam com recursos financeiros de instituições de fomento como o BID, não suportaria. No entanto, se vivemos um momento em que o aquecimento global ganha o cenário internacional e a questão das mudanças climáticas se faz presente em todas as rodadas de negociações, o planejamento do PROSAMIM que envolve diretamente a questão socioambiental, deveria ter levado em conta a alternativa, de fato, de pensar a possibilidade de garantir a existência dos igarapés em áreas urbanas da cidade de Manaus, com foco na produção de ambientes urbanos sustentáveis, mediante análise de indicadores de risco e vulnerabilidade, como aponta Ribeiro (2010), ao apresentar uma revisão da literatura acerca desses conceitos.

Segundo o BID $^{6}$ de acordo com o diagnóstico socioeconômico levantado, o principal objetivo do Programa direcionado a população com renda inferior a um salário mínimo, era o de proporcionar, por meio do acesso aos serviços de infra-estrutura básica, como água, energia e saneamento, formas de garantir melhor qualidade de vida e saúde. Estes objetivos, analisados sob a perspectiva de que os igarapés foram canalizados e a área aterrada (ainda que sem o devido tratamento do lixo acumulado) legitimam os dados do quadro abaixo que em uma série histórica registra, para o ano de 2006, menores índices de casos de doenças de veiculação hídrica nos bairros da Cachoerinha, Educandos e Centro. Localidades, respectivamente, relacionadas às áreas de intervenção do PROSAMIM, com obras iniciadas no ano de 2006, nos igarapés de Manaus, Bittencourt e Mestre Chico. No entanto, vale salientar que estes resultados são pontuais e mitigadores, visto o sistema de esgoto sanitário 
implantado consistir apenas no de coleta e não de tratamento. O que significa dizer que os dejetos continuam sendo lançados - in natura - no Rio Negro.

Quadro 1 - Casos de enfermidades, relacionadas as condições sanitárias de Bairros em Manaus, no período de 2003 a 2006.

\begin{tabular}{|c|c|c|c|c|c|c|c|c|c|c|c|c|c|}
\hline \multirow[t]{2}{*}{ Bairro } & \multirow[t]{2}{*}{$\begin{array}{l}\text { P o p . } \\
\text { Geral }\end{array}$} & \multicolumn{3}{|c|}{$\begin{array}{l}\text { Enfermidades } \\
\text { Diarréicas } \\
\text { Agudas } \\
\text { (com internação) }\end{array}$} & \multicolumn{4}{|c|}{ Hepatite A } & \multicolumn{3}{|c|}{ Leptospirose } & \multirow[b]{2}{*}{2005} & \multirow[b]{2}{*}{2006} \\
\hline & & 2003 & 2004 & 2005 & 2006 & 2003 & 2004 & 2005 & 2006 & 2003 & 2004 & & \\
\hline Cachoeirinha & 26.457 & 108 & 72 & 62 & 200 & 5 & 61 & 19 & 5 & 1 & 2 & 1 & 0 \\
\hline Centro & 36.470 & 126 & 79 & 33 & 192 & 3 & 74 & 27 & 6 & 0 & 1 & 1 & 2 \\
\hline Educandos & 17.377 & 704 & 400 & 384 & 424 & 8 & 27 & 10 & 6 & 0 & 1 & 0 & 0 \\
\hline
\end{tabular}

Fonte: Secretaria Municipal de Saúde - SEMSA ${ }^{10}$

\section{AS UNIDADES HABITACIONAIS}

Sobre os igarapés canalizados e aterrados, foram construídas Unidades Habitacionais possibilitando a valorização do uso do solo, com grave comprometimento ambiental, visto o lixo acumulado no leito dos igarapés, não ter sido totalmente retirado e, sim, compactado e, posteriormente, a área concretada. No entanto, ainda que tenha sido adotada uma metodologia de enfoque participativo, tendo constituído 32 associações, com 1129 reuniões realizadas ${ }^{7}$ não se efetivou uma participação autêntica (SOUZA, 2003), apesar da "presença dos envolvidos" em cinco audiências públicas, para discutir junto a Secretaria de Infra-estrutura e Empresa Consultora, as cinco alternativas para a solução de drenagem e reassentamento, incluindo a alternativa de não ação. E aí vale o questionamento: Como uma população com renda média inferior a um salário mínimo que nunca participou de uma reunião de tamanha importância, sem maior conhecimento das conseqüências de cada proposta a ser votada, vai ter condições de mensurar a alternativa capaz de melhor contribuir para minimizar o impacto ambiental, potencializando e maximizando com as ações a sustentabilidade dos recursos existentes, com o compromisso de gerar benefícios socioambientais? Apesar do uso da metodologia participativa, a necessidade de cumprir uma agenda, acaba por estabelecer uma gestão, de certa de forma, verticalizada e coercitiva, não se efetivando, de fato, uma participação popular com apropriação dos diferentes olhares e saberes de quem será, diretamente, afetado pelo processo. Como se pode identificar no texto abaixo,

A Empresa Consultora apresentou 5 alternativas para a solução de drenagem e reassentamento, incluindo a alternativa de não ação. As alternativas foram apresentadas e discutidas pelas equipes da SEINF e da Empresa Consultora, com as comunidades em quatro audiências públicas. A alternativa eleita foi a que propunha canais abertos e galerias, criando áreas para ocupação de moradias, infra-estrutura pública de serviços e 
de lazer, condicionando o reassentamento da população em áreas próximas ou distantes, de acordo com o desejo da família a ser reassentada (PROSAMIM, 2008).

A mesma análise se aplica a proposta do projeto da unidade habitacional- UH que ignorando um modelo de habitação adequado ao clima e ambiente amazônico, realizado pelo Instituto de Pesquisas do Amazonas - INPA edificou as UH's com material cerâmico, em blocos pré-fabricados, coberta com telhas de fibro-cimento e janelas tipo basculante. Estrutura padronizada de acordo com modelos de habitação popular que impedem a circulação do ar tornando o ambiente de dois quartos, sala, cozinha e banheiro com área útil de $54 \mathrm{~m}^{2}$ insustentável em determinados horários do dia e estações do ano.

De acordo com Batista (2005), em projetos de habitação popular que envolve o Estado como executor, é comum a população não se identificar como agente do processo. Para a autora, o fato de haver uma carência com relação ao pagamento do bem adquirido, faz com que, em um primeiro momento a população veja a casa própria como um "presente" do poder público e não uma legitimidade de sua cidadania, enquanto conquista de direitos pertinentes à escala de um espaço cidadão, cuja infra-estrutura básica de serviços, compete ao Estado realizar.

Além das melhorias urbanística, ambiental e habitacional, para o BID as ações de sustentabilidade ambiental e social, são contrapartidas para o sucesso do empreendimento. No entanto, as ações concretas ficam aquém do que, baseado na literatura se entende por sustentabilidade, visto as mesmas se resumirem a cursos de capacitação, muitas vezes sem nenhuma ligação com as demandas do mercado ou vocações locais. O que favorece o uso misto das unidades habitacionais, onde, em geral, a sala, passa a ser utilizada para o comércio como alternativa de geração de renda. E com relação às ações de sustentabilidade ambiental, em geral, as ações também mitigadoras, pelo que se pode observar até o momento, transferiram para outras localidades da cidade a vulnerabilidade aos riscos
(RIBEIRO, 2010).

Para as famílias cadastradas no PROGRAMA, quatro eram as opções de assentamentos.

Indenização - O proprietário que reside ou não no imóvel, que tem valor superior a R\$21 mil, recebe uma indenização em dinheiro equivalente ao valor de mercado da benfeitoria.

Bônus - O morador/proprietário recebe um bônus moradia no valor de até $\mathrm{R} \$ 21 \mathrm{mil}$, para aquisição de imóvel residencial, devidamente regularizado (IPTU, Água, Luz), no Estado do Amazonas, após ser avaliado pelo PROSAMIM.

Unidade Habitacional - São as novas moradias construídas em solo criado nos igarapés beneficiados pelo Programa.

Conjuntos Habitacionais - São casas em conjuntos populares localizadas na Zona Norte da Cidade avaliadas no valor de $\mathrm{R} \$ 21 \mathrm{mil}$.

Baseado nestas opções, em uma coletânea de depoimentos ${ }^{8}$, levantados em agosto de 2008, muitos moradores optaram por receber a indenização ou bônus, o que resultou em um reassentamento em áreas menos valorizadas da cidade como os bairros do Armando Mendes, Zumbi entre outras da zona leste. Neste caso, promovendo uma desterritorialização do seu local de origem - o igarapé onde viveu parte de sua vida. Para se reterritorializar em outra localidade, periférica à área central, onde os problemas com deslocamento para o trabalho; garantia de vaga na rede pública de ensino para as crianças; novas relações afetivas, entre outras formas de reprodução da vida, terão que ser construídas.

Ações que sinalizam a lógica da produção do espaço, com segregação socioespacial e valorização do solo urbano. Pressupostos para atender a racionalidade de embelezamento da cidade, conforme constatado em texto extraído em documento do projeto,

A ocupação destas zonas de alta sensibilidade ambiental, não aptas para o desenvolvimento urbano, representa um problema ambiental, social e urbanístico para a cidade. Isto gera externalidades negativas para a área central (inundação, maus odores, mosquitos e roedores) que resultam na deteriorização e abandono das áreas vizinhas com a conseqüente perda de ativos 
públicos e de valor imobiliário, promovendo a degradação das edificações e dos espaços públicos nas proximidades, afetando direta ou indiretamente a todos os habitantes da cidade. Quase todas as moradias que se encontram nas zonas de risco contam com serviços precários de eletricidade e água obtidos em sua maioria de forma clandestina. Apesar disso, estas famílias ocupam moradias com localização no Centro da cidade, próximo às fontes de emprego, de transportes coletivos, de serviços públicos, da educação e da saúde, bem como, outras infra-estruturas sociais disponíveis na área (PROSAMIM, 2008).

Para o casal, José Sérgio da Silva e Maria Eliane Corvelo Fonseca que optaram pela moradia no Conjunto Habitacional, localizado na Zona Norte da cidade e, antes habitavam no Igarapé do Quarenta - hoje espaço público de lazer, fica o seguinte depoimento:

"Para minha família foi bom, foi bom pra mim, eu morava com a minha sogra há mais de 20 anos. Então por esse lado foi bom, por ter ganho uma casa, nós mesmos não teríamos possibilidade. Mas aqui no Nova Cidade nós temos muitas dificuldades em termo de escola. Os recursos aqui são poucos tem saúde, tem educação, mas é distante outra dificuldade é a questão do desemprego. Eu sou um cara desempregado, para me locomover eu preciso do dinheiro do ônibus, antes não, era tudo perto, cinco minutos chegava no Centro, era fácil para chegar ao distrito industrial para procurar emprego, eu morei mais de 20 anos no igarapé do 40 por que eu me juntei com ela (esposa). A gente residia lá por causa das dificuldades, não tinha condições de comprar casa, eu trabalhava no distrito, e o dinheiro que eu ganhava era só para o sustento da minha família, eu só tinha condições de morar alugado, mas a minha sogra era doente e não queria se separar dela então cedeu o espaço para a gente morar.

Eu não acreditava, durante muito tempo que eu morei lá eram tantas promessas, nós nunca acreditaríamos. o processo foi mais com a minha esposa, que eu tava trabalhando. Pra nós o tratamento e o processo teve um pouco de dificuldade por que eles só queriam pagar uma indenização de $R \$ 7000,00$. Ai, nesse caso eu pulei! Como vão pagar $R \$ 7.000,00$ por uma casa? Como a gente vai fazer? Não tem condições. Ai nós viramos o jogo! Foi feito um novo acordo, vieram ver como era a situação, ai fomos lá discutimos, dialogamos e ai acertamos. A mãe dela optou pelo Bônus, esta morando na Cidade Nova e nós ganhamos uma casa no conjunto.

Nesta casa graças a Deus nós estamos bem, estamos embaixo de um teto. Algumas questões podem melhorar como saúde e educação. Eu gostaria de agradecer a educação que tiveram com a gente sempre trataram a gente muito, bem trouxeram a gente aqui, a nossa mudança deu tudo certo.

Da equipe do prosamim não tenho nada o que falar, nós estamos participando dos cursos. Eu (esposa) fiz da Cozinha Brasil e os PAS que é de higiene mas o certificado ainda não chegou.

As codornas estão ai, mas eu tenho uma crítica algumas famílias estão recebendo ração boa e outras ruim quem recebe ração boa a codorna dá ate 50 ovos por dia e as nossas só dão sete ou oito.

Mas já estão rendendo às vezes o pessoal da família vem pede ai a gente dá por que já está todo mundo vendendo!!!"'. 


\section{Considerações finais}

Considerando como pressuposto para o desenvolvimento local a efetiva participação popular e entendendo que entre os envolvidos ocorreram vários deslocamentos para outros bairros da cidade desagregando-os enquanto elementos identitários da história dos igarapés de Manaus, Bittencourt e Mestre Chico fica para reflexão, o que cita Smith e Owens (1996) quando afirmam que o capitalismo global parece gerar prosperidade, mas, simultaneamente também empobrece uma porção significativa da sociedade. Neste contexto os resultados com o Programa Social e Ambiental dos Igarapés de Manaus atenderam à lógica da racionalidade da produção do espaço com a valorização do uso do solo tanto das áreas canalizadas e aterradas de igarapés, como do seu entorno. A magnitude do projeto e o desafio na implantação têm seus méritos. No entanto, se faz necessário avançar no sentido de, a partir deste programa, pensar outros modelos possíveis para assentamentos populacionais em áreas com características socioeconômicas e ambientais similares, buscando metodologias que possibilitem agregar ao planejamento as efetivas contribuições dos atores envolvidos. Isso demanda um tempo. Demanda pensar os projetos de inclusão social e preservação ambiental, não como projetos de governo, mas, sim, projetos de uma sociedade civil organizada.

Talvez este, seja o caminho a seguir com relação ao planejamento e gestão em demandas desta magnitude, que por envolver altos investimentos financeiros e fiança pública, necessitam efetivamente como resultado, garantir uma melhor oportunidade de acesso equitativo para todos, na perspectiva de ver no território a possibilidade de usá-lo de forma sustentável através de novas relações onde a natureza seja tanto abrigo como recurso do homem, que sabendo do seu valor garantirá o uso com foco no desenvolvimento local baseado nos princípios da sustentabilidade.

\section{Notas}

1. Igarapé - Palavra indígena para um rio pequeno que tem as mesmas características de um rio grande.

2. www.cqgp.sp.gov.br/gt_licitacoes/publicacoes/ joanesburgo.pdf -. Acesso em 24 de julho de 2010

3. Vale lembrar que Joanesburgo é a capital financeira da África do Sul e Cidade do Cabo a capital legislativa.

4. Para aprofundar o contexto teórico ler Ribeiro (2008).

5. http://idbdocs.iadb.org/wsdocs/ getdocument.aspx?docnum $=35074616$. Acessado em 26 de julho de 2010.

\section{BIBLIOGRAFIA}

BATISTA, Selma Paula Maciel. Candeal Pequeno: Um Território Usado. Dissertação. UFBA:BA, 2005. $150 \mathrm{p}$.

BROSE, Markus. Fortalecendo a democracia e
6. http://idbdocs.iadb.org/wsdocs/ getdocument.aspx?docnum $=35074616$. Acessado em 26 de julho de 2010.

\section{Estudo de caso PROSAMIM (2008)}

8. De acordo com entrevistas realizadas por Viviane e Andreza em agosto de 2008, Trabalho acadêmico

9. De acordo com entrevistas realizadas por Viviane e Andreza em agosto de 2008, Trabalho acadêmico.

10. (SEMSA apud Estudo de caso PROSAMIM (2008)) do desenvolvimento local: 103 experiências inovadoras no meio rural gaúcho. Santa Cruz do Sul. EDUNISC, 2000. 451 p.

BUARQUE, Sérgio C. Construindo o Desenvolvimento Local Sustentável. Rio de Janeiro. Garamond, 1999. $180 \mathrm{p}$. 
OLIVEIRA, José Aldemir de. Manaus de 1920 1967: a cidade doce e dura em excesso. Manaus: EDUA: VALER, 2003. $176 \mathrm{p}$.

PROSAMIM. Estudo de Caso. Manaus: AM, 2008. $19 \mathrm{p}$.

RIBEIRO, Wagner C. A ordem ambiental internacional. São Paulo. Contexto, 2008. 2a edição. 176 p.

RIBEIRO, Wagner C. Riscos e vulnerabilidade urbana no Brasil. Scripta Nova (Barcelona), v. XIV, num. 331 p. $65,2010$.

SACHS, Ignacy. Desenvolvimento Includente, Sustentável e Sustentado. Rio de Janeiro. Garamond. 2004. 151 p.

SANTOS, Milton. O espaço do cidadão. São Paulo. Studio Nobel. 2000. $5^{a}$ edição
Nobel, 1985. 142 p.

Espaço e Método - São Paulo:

A Natureza do Espaço. Técnica e Tempo. Razão e Emoção. São Paulo: Hucitec, 1996. $308 \mathrm{p}$.

Técnica Espaço e Tempo - Globalização e Meio Técnico-Científico Informacional, São Paulo: Hucitec, 1997. $3^{a}$ edição. 190 p.

SMITH, Tim Bayliss e OWENS, Susan. O desafio ambiental. In: Geografia Humana: Sociedade, Espaço e Ciência Social. (org.) DEREK, Gregory, MARTIN, Ron e Smith, Graham. Rio de Janeiro: Jorge Zahar Ed., 1996. p 125-158

SOUZA, Marcelo Lopes. Mudar a Cidade: Uma introdução crítica ao planejamento e à gestão urbanos. Rio de Janeiro:Bertrand Brasil, 2003 $560 \mathrm{p}$. 